\title{
REVIEW
}

\section{Macrophage migration inhibitory factor: a neuroendocrine modulator of chronic inflammation}

\author{
J A Baugh and S C Donnelly \\ Department of Medicine and Therapeutics, The Conway Institute of Biomolecular and Biomedical Research, University College Dublin, Belfield, Dublin 4, \\ Ireland \\ (Requests for offprints should be addressed to J A Baugh; Email: John.Baugh@ucd.ie)
}

\begin{abstract}
The diverse actions of macrophage migration inhibitory factor (MIF) within the immuno-neuroendocrine system are yet to be fully understood, but it is clear that MIF plays a pivotal role in the regulation of both the innate and adaptive immune response. An emerging body of data presently indicates that MIF's position within the cytokine cascade is to act in concert with glucocorticoids to control the 'set point' and magnitude of the immune and inflammatory response.

In this article we will review the actions of MIF within the immune system and discuss the overlapping and

contrasting aspects of MIF and glucocorticoid biology. In particular we will focus on the role of MIF within the immuno-neuroendocrine interface and suggest molecular mechanisms by which MIF may counter-regulate glucocorticoid function. Finally we will discuss emerging evidence that functional MIF gene-promoter polymorphisms render one susceptible to elevated MIF expression, and the development of an exaggerated immune/ inflammatory response that potentiates the progression to chronic inflammatory disease.

Journal of Endocrinology (2003) 179, 15-23
\end{abstract}

\section{Introduction}

Macrophage migration inhibitory factor (MIF) has been well described as a potent pro-inflammatory mediator, but is now emerging as a key integrator of the immunoneuroendocrine interface. MIF was originally described in 1966 as a T-lymphocyte-derived 'activity' that inhibited the random migration of macrophages (Bloom \& Bennett 1966, David 1966). Over the subsequent 20 years, MIF expression was found to correlate with general macrophage activation functions including adherence, spreading, phagocytosis and enhanced tumoricidal activity (Nathan et al. 1971, 1973, Churchill et al. 1975). More recently, following the cloning and expression of recombinant protein, and the development of specific anti-MIF antibodies, it has become apparent that MIF is an important modulator of inflammatory and immune responses (reviewed by Baugh \& Bucala 2002).

Although originally described as a T-lymphocyte product, studies in the early 1990s aimed at identifying novel mediators that could counter-regulate the effects of glucocorticoids on inflammation and immunity led to the discovery that MIF is released by cells of the anterior pituitary gland (Bernhagen et al. 1993). It was shown that MIF accounts for approximately $0.05 \%$ of the total pituitary content (Bernhagen et al. 1993, Nishino et al. 1995) as compared with adrenocorticotropin (ACTH) (0.2\%; Thomer et al. 1992) and prolactin (0.08\%; Frantz \& Wilson 1992). Further studies in rodents suggested that production of MIF by the pituitary gland might be an integral part of the host's systemic stress response. When mice received an i.p. injection of lipopolysaccharide (LPS), there was a dramatic fall in the pituitary content of MIF, a concomitant increase in plasma levels of MIF, and a gradual elevation of MIF mRNA expression in pituitary tissues (Bernhagen et al. 1993, Calandra et al. 1995, Nishino et al. 1995). Circulating MIF levels in animals were also seen to rise 3-4 h after exposure to handling-induced stress, similar to the more classically described stress-related increases in circulating ACTH and glucocorticoid levels (Calandra et al. 1995). Further studies demonstrated that MIF was actually produced at all levels of the hypothalamo-pituitary-adrenal axis (Bacher et al. 1998) and that pituitary expression of MIF was induced by corticotropin-releasing factor (CRF) in a cAMP-dependent manner (Waeber et al. 1998). MIF was thus 'rediscovered' as a pituitary-derived mediator of systemic stress responses (reviewed by Bucala 1996).

\section{MIF and innate immunity}

Studies carried out with hypophysectomized mice demonstrated that the monocyte/macrophage was an 
important producer of MIF in response to bacterial infection (Calandra et al. 1994). Like anterior pituitary cells, macrophages contain a significant amount of pre-formed MIF within intracellular pools that is rapidly released upon stimulation. This is in contrast to other pro-inflammatory cytokines such as interleukin (IL)-1 $\beta$ and tumor necrosis factor (TNF) $-\alpha$ that require de novo mRNA generation and protein synthesis before secretion is observed. MIF secretion from macrophages is not only rapid but occurs with LPS concentrations that are 10- to 100-fold lower than those required to induce TNF- $\alpha$ production (Calandra et al. 1994). Upon release, MIF is directly pro-inflammatory by activating or promoting cytokine expression (TNF- $\alpha$ (Calandra et al. 1994, 2000), IL-1 $\beta$, IL-2 (Bacher et al. 1996), IL-6 (Calandra et al. 1994, Satoskar et al. 2001), IL-8 (Benigni et al. 2000), interferon (IFN)- $\gamma$ (Bacher et al. 1996, Abe et al. 2001)), nitric oxide release (Bernhagen et al. 1994a), matrix metalloproteinase expression (Meyer-Siegler 2000, Onodera et al. 2000, 2002), and induction of the cyclooxygenase-2 pathway (Mitchell et al. 1999).

LPS-induced secretion of MIF from the pituitary gland and from circulating/tissue-resident monocyte/ macrophages is thought to play an important role in the pathogenesis of endotoxemia and sepsis. In vivo studies in rats have shown that MIF protein is released from the pituitary, adrenal gland, lung, liver, spleen, kidney and skin within 6 h of LPS injection (Bacher et al. 1997). Treatment of mice with recombinant MIF has been shown to potentiate lethal endotoxemia (Bernhagen et al. 1993) and MIF's therapeutic potential has been highlighted by the ability of neutralizing anti-MIF antibodies to protect animals in models of severe sepsis. Of clinical importance, this protection has been observed when given before and up to $8 \mathrm{~h}$ after the initiating septic insult (Calandra et al. 2000). Several studies have provided clinical evidence for systemically elevated MIF expression during sepsis. In addition to studies carried out by Calandra et al., Beishuizen and colleagues serially measured serum MIF, cortisol, plasma ACTH, TNF- $\alpha$ and IL-6 in 40 critical-care patients over a period of 14 days or until discharge or death. On day 1 , MIF levels were significantly elevated in septic shock patients compared with multi-trauma patients and normal controls (Beishuizen et al. 2001). Furthermore, the timecourse of MIF expression in serum paralleled that of cortisol in the septic shock patients. A significant correlation was also observed between elevated MIF levels upon admission and occurrence of death. Interestingly, MIF levels were not elevated in non-septic multi-trauma patients (Beishuizen et al. 2001). These data were complemented by Joshi et al. (2000), who reported elevated MIF levels in multi-trauma patients that correlated with positive tests for bacterial cultures in blood, urine, sputum or at the wound site. With the development of MIF knock-out mice, it has become apparent that these animals are relatively resistant to LPS (Bozza et al. 1999). Similarly, LPS-induced nuclear factor $-\kappa B \quad(N F-\kappa B)$ activity and steady-state TNF- $\alpha$ mRNA levels are markedly reduced by antisense MIF treatment of macrophages. By contrast, antisense MIF macrophages exhibited normal responses to other inflammatory stimuli, including Gram-positive bacteria (Froidevaux et al. 2001). Investigators have recently shown that this is due to downregulation of Toll-like receptor-4, the signal transducing molecule of the LPS receptor complex, and is associated with decreased activity of the transcription factor PU.1 that is required for optimal expression of the Tlr 4 gene in myeloid cells (Roger et al. 2001).

Given the prior association of MIF with delayed-type hypersensitivity (DTH) and immune cell activation it is somewhat surprising that MIF is released from the same pituitary cell type that secretes ACTH, a mediator that stimulates the adrenal secretion of glucocorticoids, potent anti-inflammatory hormones. In addition to being secreted from the pituitary, MIF is also found to be released from immune/inflammatory cells as a consequence of glucocorticoid stimulation (Calandra et al. 1995, Bacher et al. 1996, Leech et al. 2000). Recombinant MIF 'overrides' or counter-regulates the immunosuppressive effects of glucocorticoids on immune/inflammatory cell activation and pro-inflammatory cytokine release. Specifically, MIF has been shown to counteract glucocorticoid-induced inhibition of inflammatory cytokine secretion in macrophages (Calandra et al. 1994), $\mathrm{T}$ cells (Bacher et al. 1996) and synovial fibroblasts (Leech et al. 1999, Santos et al. 2001). An emerging body of data presently indicates that MIF's position within the cytokine cascade is to act in concert with glucocorticoids to control the 'set point' of the immune and inflammatory response (Fig. 1).

\section{MIF and adaptive immunity}

While MIF was originally described as a T-cell product involved in DTH responses, the current view of MIF function favors a dominant role for MIF in the innate immune response. MIF is nevertheless an important regulator of cognate immunity. Stimulation of primary $\mathrm{T}$ cells with anti-CD3 antibody or superantigen was found to induce MIF mRNA expression and protein secretion (Bacher et al. 1996, Calandra et al. 1998). Neutralization of T-cell-derived MIF with specific anti-MIF antibodies inhibits both anti-CD3- and superantigen-induced IL-2 secretion and reduces $\mathrm{T}$-cell proliferation by $40-60 \%$ (Bacher et al. 1996). In vivo, treatment of mice with anti-MIF antibodies inhibits antigen-driven T-cell proliferation and reduces the expression of antigen-specific IgG production (Bacher et al. 1996). A role for MIF in the shaping of the adaptive immune response is supported by expression studies using $\mathrm{T}_{\mathrm{H}} 1$ and $\mathrm{T}_{\mathrm{H}} 2 \mathrm{~T}$-cell subsets. In parallel to effects seen in vivo it was found that while both subsets of $\mathrm{T}$ cells express MIF, secretion is predominantly increased in activated $\mathrm{T}_{\mathrm{H}} 2$ clones. These data 

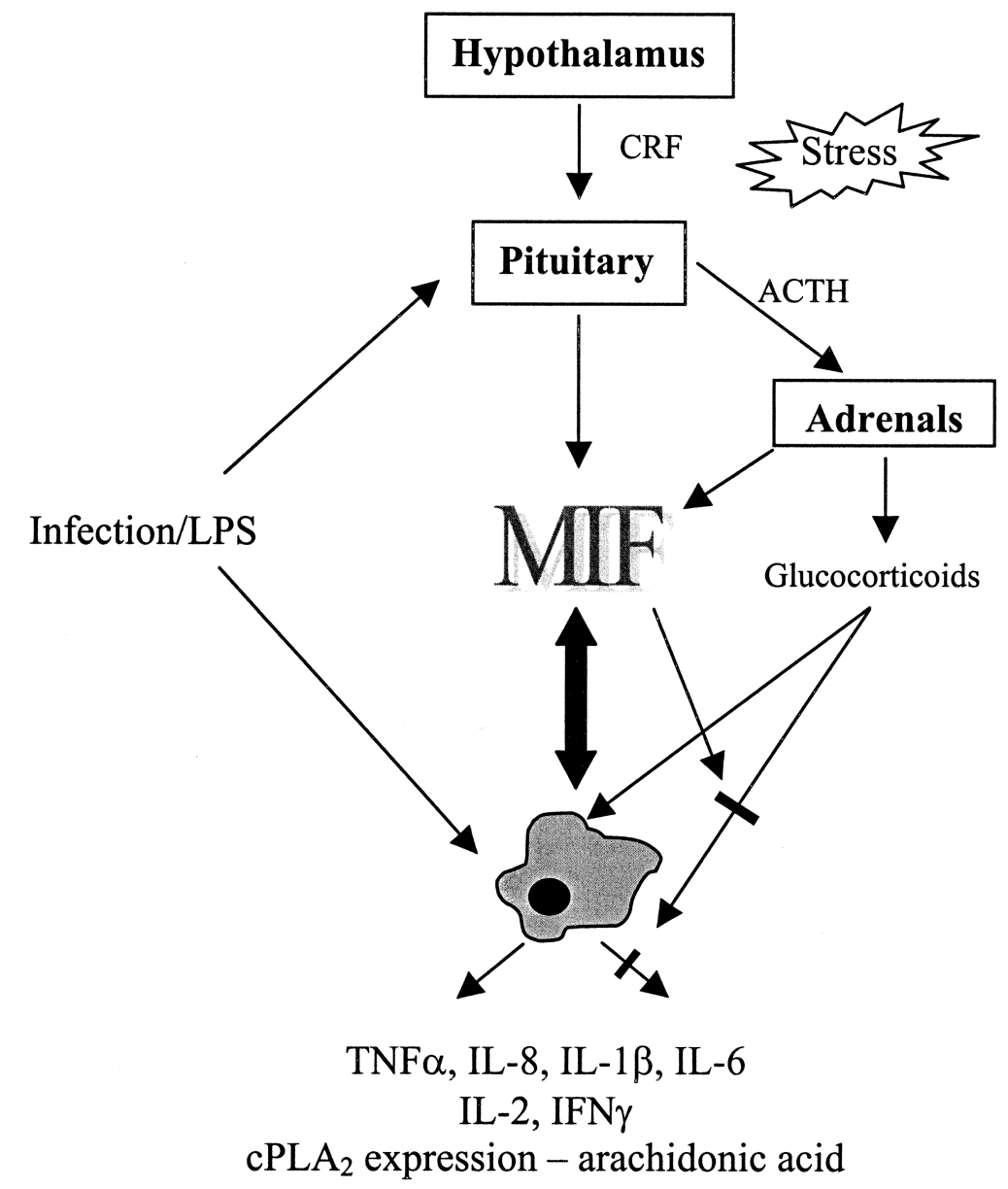

Figure 1 Position of MIF within the immuno-neuroendocrine interface (adapted from Bucala 1996). MIF is rapidly produced by the pituitary and cells of the monocyte/ macrophage lineage in response to infection and stress. Within the inflammatory milieu, MIF can counteract the anti-inflammatory actions of glucocorticoids and promote the production of inflammatory cytokines. The potential importance of MIF within the immuno-neuroendocrine interface is further highlighted by the fact that low concentrations of glucocorticoids actually stimulate the production of MIF. Thus we see MIF as a glucocorticoid-induced modulator of the immuno-neuroendocrine system.

would favor a role for MIF in the development of $\mathrm{T}_{\mathrm{H}}$ 2-driven antibody production.

\section{MIF in inflammatory lung disease}

Acute respiratory distress syndrome (ARDS) is a lifethreatening, hyperacute inflammatory response that occurs in the lungs following trauma or sepsis. Inflammatory cell activation, and in particular neutrophil activation, has been implicated in the early stages of ARDS pathogenesis (Powe et al. 1982, Donnelly et al. 1994a, b, Chollet-Martin et al. 1996).

MIF has been demonstrated to play a key role in acute lung injury (Donnelly et al. 1997), highlighted by its ability to accentuate pro-inflammatory cytokine production in ex vivo alveolar cells derived from patients with ARDS. Further studies showed that MIF could counterregulate the anti-inflammatory effects of glucocorticoids on alveolar macrophage cytokine expression (Donnelly et al. 1997). Recent clinical studies have confirmed these findings and have shown that increased MIF expression correlates with the development of ARDS in septic patients (Beishuizen et al. 2001).

In a rat model of lung injury, anti-MIF treatment was shown to reduce the accumulation of activated neutrophils in the lungs (Makita et al. 1998). Bronchoalveolar lavage (BAL) samples from these animals were found to contain significantly reduced levels of the neutrophil 
chemoattractant macrophage inflammatory protein-2 (MIP-2). As MIF is not itself a chemoattractant for neutrophils (S C Donnelly, unpublished observations) these data suggest that MIF may play a role in ARDS via upregulation of the neutrophil chemoattractant MIP-2 (Makita et al. 1998).

These data suggest that overproduction of MIF in the lung during acute trauma could lead to neutrophilia that is refractory to suppression by both endogenous and therapeutic glucocorticoids. Clinical treatment with anti-MIF strategies may help reduce early neutrophil accumulation in ARDS and increase the effectiveness of glucocorticoid treatment.

Recent studies carried out by Tanino et al. (2002) have also favored a role for MIF in the development of acute lung injury. Using a mouse model of lung injury and fibrosis it was shown that intratracheal administration of bleomycin induced a rapid elevation in MIF expression in both lung tissues and BAL fluids. Treatment of mice with a neutralizing anti-MIF antibody resulted in significantly reduced accumulation of inflammatory cells and reduced TNF- $\alpha$ expression in alveolar airspaces at day 7 , decreased histopathological lung injury score at day 10 , and decreased mortality by day 14 . Anti-MIF treatment, however, did not appear to influence markers of lung fibrosis at day 21 in this model. These data highlight a role for MIF in the initiation of acute lung injury.

We have recently identified human eosinophils, derived from atopic donors, as potent sources of MIF. Both C5a and IL-5, physiologically relevant stimuli in allergic inflammatory disease, caused significant immediate release of MIF from these ex vivo circulating cells (Rossi et al. 1998). Eosinophils have been implicated as a key cell type in the pathogenesis of allergic inflammatory diseases such as bronchial asthma, allergic rhinitis and atopic dermatitis (Thomas \& Warner 1996, Kay et al. 1997). Analysis of BAL samples from a cohort of stable asthmatics revealed an elevated level of MIF protein expression and it is suggested that the elevated numbers of eosinophils present in the alveolar airspaces are responsible for its production (Rossi et al. 1998). The identification of eosinophils, and notably the type II alveolar epithelial cells (Donnelly et al. 1997) as additional cellular sources of MIF, and the correlation of MIF expression with the development of a $\mathrm{T}_{\mathrm{H}} 2$ phenotype highlights the potential importance of MIF in allergic pulmonary inflammatory disease.

\section{Molecular mechanism of action of MIF}

A specific signaling MIF receptor has yet to be described; several lines of data have converged for how MIF may induce signal transduction and modulate cell responses. Studies by Mitchell et al. (1999) have shown that exogenously added recombinant MIF as well as endogenously released MIF - which is secreted as a consequence of serum stimulation - induces the proliferation of quiescent fibroblasts. This response was associated with a sustained activation of the p44/p42 ERK subfamily of mitogenactivated protein (MAP) kinases and was dependent upon the activity of protein kinase A (Mitchell et al. 1999). The ERK MAP kinase signaling cascade results in the phosphorylation and activation of a number of cytosolic proteins such as $\mathrm{P} 90^{\mathrm{rk}}, \mathrm{c}-m y c$ and cytoplasmic phospholipase $\mathrm{A}_{2}\left(\mathrm{cPLA}_{2}\right)$ (Denhardt 1996). cPLA 2 is a critical mediator of inflammatory responses (Hayakawa et al. 1993) and its product, arachidonic acid, is the precursor for the synthesis of prostaglandins and leukotrienes. Further studies went on to show that MIF could induce the phosphorylation and activation of $\mathrm{CPLA}_{2}$ and, ultimately, the release of arachidonic acid by an ERK- but not p38-MAP kinasedependent mechanism (Mitchell et al. 1999). Interestingly, ${ }_{\text {cPLA }}$ is an important target for the anti-inflammatory action of glucocorticoids and the ability of MIF to activate cPLA $_{2}$ may be one mechanism by which MIF regulates glucocorticoid action to alter the set point of the inflammatory/immune response. In support of this hypothesis, MIF was able to counter-regulate glucocorticoid inhibition of TNF- $\alpha$-induced arachidonic acid release from L929 fibroblasts (Mitchell et al. 1999).

Another possible mechanism by which MIF may modulate inflammatory responses and counter-regulate the effects of glucocorticoids is via effects on NF- $\kappa B$ activity. $\mathrm{NF}-\kappa \mathrm{B}$ is an important regulator of inflammatory cytokine gene expression (Barnes \& Karin 1997) and several lines of evidence suggest that glucocorticoids may inhibit the production of inflammatory mediators such as TNF- $\alpha$ via modulation of NF- $\mathrm{KB}$ activity. Glucocorticoids have been proposed to inhibit binding of the p65 subunit of NF- $\kappa B$ to the transcriptional machinery of target genes (De Bosscher et al. 2000) and to induce IKB synthesis (Auphan et al. 1995, Scheinman et al. 1995). Elevation of cytoplasmic I $\kappa B$ inhibits the ability of NF- $\kappa B$ to translocate to the nucleus whereas inhibition of NF- $\kappa B$ p 65 binding to DNA directly inhibits expression of target genes. Recent studies have shown that treatment with MIF inhibits the ability of glucocorticoids to induce I $\mathrm{KB}$ synthesis in LPS-stimulated human peripheral blood mononuclear cells (Daun \& Cannon 2000). Thus, by blocking glucocorticoid-induced IאB synthesis, MIF promotes the translocation of NF- $\mathrm{KB}$ into the nucleus where it activates pro-inflammatory cytokine and adhesion molecule expression.

Recent studies by Kleeman et al. (2000) have shown that MIF may directly affect transcriptional activity of activator protein-1 (AP-1)-responsive genes via an interaction with Jab. AP-1 is a transcription factor that binds DNA as a heteromeric complex with the Fos and Jun oncoproteins and it is proposed that Jab-1 stabilizes the binding of AP-1/c-jun complexes to AP-1 sites (Claret et al. 1996). Jab-1 also binds and promotes the degradation of $\mathrm{p} 27^{\mathrm{Kip} 1}$, a protein that halts the cell-division cycle. 
The interaction of MIF with Jab-1 was confirmed in vivo and was shown to result in the inhibition of Jab-1 binding to c-jun, thus destabilizing the formation of activated AP-1 complexes. The binding of MIF to Jab-1 resulted in reduced degradation of $\mathrm{p} 27^{\mathrm{Kip} 1}$ and MIF overexpression inhibited the growth-promoting properties of Jab-1 in fibroblast cells (Kleeman et al. 2000). As AP-1 has been shown to be an important regulator of several proinflammatory genes these data at first appear to conflict with the pro-inflammatory nature described for MIF. Similarly, the cell-growth-promoting effects of MIF reported by others (Hudson et al. 1999, Mitchell et al. 1999, 2002) would conflict with the proposed role of MIF in the enhancement of $\mathrm{p} 27^{\mathrm{kip} 1}$-regulated cell-cycle stasis. However, one characteristic feature of MIF action is its bell-shaped dose-response curve with respect to several biological phenomena, such as its inhibition of macrophage migration (Bernhagen et al. 1994b). This implies that low vs high levels of MIF may have distinct regulatory effects on cellular processes such as Jab-1-dependent regulation of AP-1 and p27 ${ }^{\text {Kip } 1}$. Furthermore, these data highlight a fascinating overlap between MIF and glucocorticoidmediated responses. It is becoming widely accepted that an important mechanism of glucocorticoid action is the ability to trans-repress AP-1- and NF- $\kappa \mathrm{B}-$-regulated genes (Karin 1998) and that steroid-resistant disease is often associated with increased AP-1 activity (Adcock et al. 1995). The ability of MIF to regulate AP-1 stability and IкB synthesis places this mediator in a fundamentally important position to influence the activity of both endogenous and exogenous glucocorticoids.

The cell-growth-promoting properties of MIF may indeed be an important mechanism by which MIF contributes to the pathology of various inflammatory diseases. During the response to infection the innate immune response is kept in check by specialized counter-regulatory mechanisms such as apoptosis or programmed cell death (Ohmori \& Hamilton 1994). Exaggerated apoptosis in T cells is a well-reported phenomena during sepsis and is thought to contribute to the development of immune suppression (reviewed by Oberholzer et al. 2001). Similarly, defective apoptosis of activated macrophages may lead to a prolonged inflammatory response. Data reported by Hudson et al. (1999) have linked the actions of MIF to the inhibition of the tumor suppressor p53. These data were extended by Mitchell et al. (2002), who have recently shown that MIF sustains macrophage survival and pro-inflammatory function by suppressing activationinduced, p53-dependent apoptosis. Macrophage apoptosis has been proposed to be a significant contributor to the depression of the host immune response late in sepsis (Ayala et al. 1996, Williams et al. 1997).

Furthermore, it has been shown that adhesion-induced fibroblast MIF secretion promotes integrin-dependent activation of MAP kinase, cyclin D1 expression and DNA synthesis (Liao et al. 2002). Cyclin D1 is an important upstream modulator of the tumor suppressor protein retinoblastoma $(\mathrm{Rb})$, phosphorylation of which in turn releases the transcription factor E2F and subsequently induces expression of critical S-phase enzymes (Weinberg 1995). Liao et al. (2002) demonstrated that MIF plays a significant role in integrin-mediated cell-cycle progression via the induction of $\mathrm{Rb}$ phosphorylation and $\mathrm{E} 2 \mathrm{~F}$ activity, and that embryonic fibroblasts from MIF knock-out mice were refractory to malignant cell transformation induced by oncogenic $\mathrm{H}-\mathrm{ras}^{\mathrm{v} 12}$. These studies were complemented by Sasaki et al. (2002), who showed that antisense MIF treatment of solid colon 26 tumors in vivo and KM12SM cells in vitro resulted in decreased tumor size, decreased cell proliferation and decreased transcriptional activation of $\mathrm{Rb}$ and E2F. A similar study also showed that antisense attenuation of MIF expression in the colon adenocarcinoma cell line DLD-1 resulted in a significant shift from S- to G1-phase of the cell cycle accompanied by a concomitant inhibition of proliferation, increase in p21 and p53 expression and increase in STAT-1 activation (Yasuda et al. 2002).

The ability of MIF to regulate MAP kinase activation, cyclin $\mathrm{D} 1$ expression and $\mathrm{Rb}$ phosphorylation may be a critical point at which MIF can counteract the effects of glucocorticoids. In airway smooth muscle cells dexamethasone has been shown to inhibit thrombin-induced cyclin $\mathrm{D}$ mRNA expression, $\mathrm{Rb}$ phosphorylation, and subsequent cell proliferation (Fernandes et al. 1999). Similarly, in vascular smooth muscle cells dexamethasone induces cell-cycle arrest in the late G1-phase accompanied by a significant decrease in $\mathrm{Rb}$ phosphorylation (Reil et al. 2000). The molecular mechanism by which $\mathrm{Rb}$ affects glucocorticoid responses is thought to involve E2F as well as a direct interaction between glucocorticoid receptors (GR) and $\mathrm{Rb}$. Glucocorticoid-induced apoptosis has been shown to be dependent upon the $\mathrm{Rb}$ binding of the transcriptional coactivator hBRM and subsequent potentiation of GR-induced transcription of target genes (Singh et al. 2001). In parallel, dexamethasone-induced hypophosphorylation of $\mathrm{Rb}$ results in decreased activation of E2F-responsive genes and subsequent cell-cycle arrest (Greenberg et al. 2002).

A likely scenario can now be envisaged whereby MIF's prime role in the immune/inflammatory response is to regulate the infiltration, induce the activation, and promote the survival of inflammatory cells. Inappropriate expression of MIF could counter-regulate Rb/E2Fdependent effects of glucocorticoids and tip the neuroendocrine balance in favor of cell proliferation/survival, an exaggerated inflammatory response, and the development of chronic disease.

\section{Genetic susceptibility to enhanced MIF expression}

The concept that genetic polymorphisms may underlie human autoimmune/inflammatory diseases has evolved 

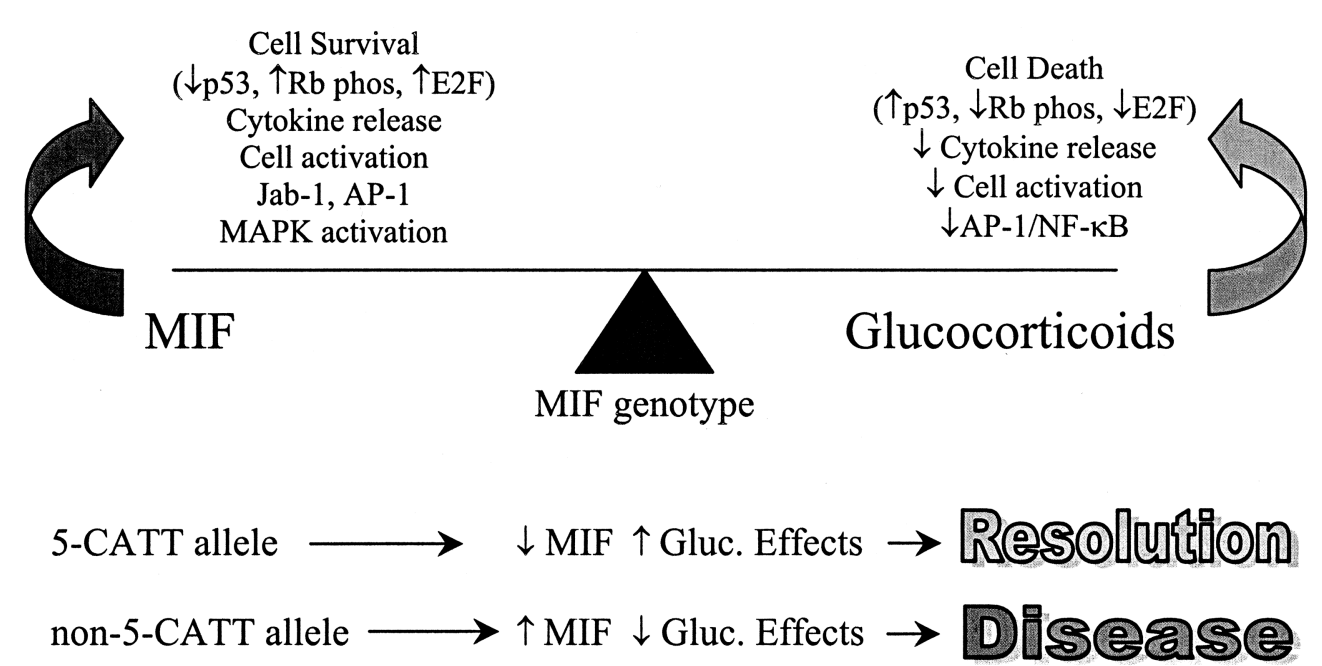

Figure 2 Putative pivotal role played by one's MIF genotype in determining the outcome of immune/inflammatory responses. We picture a fine balance between the pro-inflammatory effects of MIF and the anti-inflammatory effects of glucocorticoids that is ultimately dictated by one's ability to express the MIF gene. We propose that one's MIF genotype renders one susceptible to enhanced MIF expression and exaggerated inflammatory responses.

over many years. From the simple observation of inheritable diseases emerged the identification of gene variations that can either confer disease susceptibility or affect disease severity. Mutations in the coding regions of genes, which result in amino acid substitutions, usually cause overt forms of disease, e.g. early-onset familial forms. We believe that polymorphisms in regulatory regions are likely to be more subtle than drastic coding changes and that the effects could possibly accumulate over a longer period of time and thus contribute to the more common sporadic forms of disease that are seen later in life. Currently, only a fraction of identified polymorphisms have been shown to be both functionally significant and of prognostic value in specific disease states. Classic examples include both the TNF- $\alpha$ and IL-1 receptor antagonist polymorphisms that have been shown to be of prognostic significance in malaria, ischemic heart disease and cryptogenic fibrosing alveolitis (McGuire et al. 1994, Francis et al. 1999, Whyte et al. 2000).

We have recently described a novel functional MIF gene-promoter polymorphism that correlates with disease severity in rheumatoid arthritis (Baugh et al. 2002). Individuals were shown to be homozygous or heterozygous for 5-, 6-, 7- or 8-CATT repeats at position -794 of the promoter region and reporter assays demonstrated that the 5-CATT allele gave significantly lower transcriptional activity than the other polymorphic alleles. Analyzing a cohort of patients with a chronic inflammatory disorder, namely rheumatoid arthritis, revealed that patients carrying at least one 5-CATT allele had less aggressive rheumatoid disease. These data are consistent with the 5-CATT allele mediating a low level of MIF expression and being 'protective' for chronic persistent inflammatory disease.

Interestingly, Donn et al. (2001) also described a G to $\mathrm{C}$ single nucleotide polymorphism at position -173 of the MIF gene and correlated this mutation with disease severity in juvenile idiopathic arthritis. We are currently studying linkage data between the two polymorphic regions and believe that there is a strong possibility of a disease-associated haplotype. Furthermore, we believe that an individual's MIF genotype renders them susceptible to enhanced MIF expression and predisposes towards an exaggerated inflammatory response that potentiates chronic inflammatory disease. The ability of MIF to counter-regulate the effects of both endogenous and exogenous glucocorticoids highlights the potential importance that this functional polymorphism may have on disease outcome (Fig. 2). Genetic susceptibility to enhanced MIF expression in the neuroendocrine system may be a critical determinant in the pursuit of therapeutic strategies and strongly influence the efficacy of glucocorticoid treatment.

\section{Funding}

The authors would like to thank the Irish Lung Foundation, the Wellcome Trust and Science Foundation Ireland for financial support. 


\section{References}

Abe R, Peng T, Sailors J, Bucala R \& Metz CN 2001 Regulation of the CTL response by macrophage migration inhibitory factor. Journal of Immunology 166 747-753.

Adcock IM, Lane SJ, Brown CR, Peters MJ, Lee TH \& Barnes PJ 1995 Differences in binding of glucocorticoid receptor to DNA in steroid-resistant asthma. Journal of Immunology 154 3500-3505

Auphan N, DiDonato JA, Rosette C, Helmberg A \& Karin M 1995 Immunosuppression by glucocorticoids: inhibition of NF-kappa B activity through induction of I kappa B synthesis. Science $\mathbf{2 7 0}$ 286-290.

Ayala A, Urbanich MA, Herdon CD \& Chaudry IH 1996 Is sepsisinduced apoptosis associated with macrophage dysfunction? Journal of Trauma 40 568-573.

Bacher M, Metz CN, Calandra T, Mayer K, Chesney J, Lohoff M, Gemsa D, Donnelly T \& Bucala R 1996 An essential regulatory role for macrophage migration inhibitory factor in T-cell activation. PNAS 93 7849-7854.

Bacher M, Meinhardt A, Lan HY, Mu W, Metz CN, Chesney JA, Calandra T, Gemsa D, Donnelly T, Atkins RC et al. 1997 Migration inhibitory factor expression in experimentally induced endotoxemia. American Journal of Pathology 150 235-246.

Bacher M, Meinhardt A, Lan HY, Dhabhar FS, Mu W, Metz CN, Chesney JA, Gemsa D, Donnelly T, Atkins RC et al. 1998 MIF expression in the rat brain: implications for neuronal function. Molecular Medicine 4 217-230.

Barnes PJ \& Karin M 1997 Nuclear factor-kappaB: a pivotal transcription factor in chronic inflammatory diseases. New England Journal of Medicine 336 1066-1071.

Baugh JA \& Bucala R 2002 Macrophage migration inhibitory factor. Critical Care Medicine 30 S27-S35.

Baugh JA, Chitnis S, Donnelly SC, Monteiro J, Lin X, Plant BJ, Wolfe F, Gregersen PK \& Bucala R 2002 A functional promoter polymorphism in the macrophage migration inhibitory factor (MIF) gene associated with disease severity in rheumatoid arthritis. Genes and Immunity 3 170-176.

Benigni F, Atsumi T, Calandra T, Metz C, Echtenacher B, Peng T \& Bucala R 2000 The proinflammatory mediator macrophage migration inhibitory factor induces glucose catabolism in muscle. Journal of Clinical Investigation 106 1291-1300.

Bernhagen J, Calandra T, Mitchell RA, Martin SB, Tracey KJ, Voelter W, Manogue KR, Cerami A \& Bucala R 1993 MIF is a pituitary-derived cytokine that potentiates lethal endotoxemia. Nature 365 756-759.

Bernhagen J, Calandra T, Mitchell RA, Voelter W, Cerami A \& Bucala R 1994a Purification and characterization of the cytokine macrophage-migration inhibitory factor (MIF). FASEB Journal 8 A1417.

Bernhagen J, Mitchell RA, Calandra T, Voelter W, Cerami A \& Bucala R 1994b Purification, bioactivity, and secondary structureanalysis of mouse and human macrophage-migration inhibitory factor (MIF). Biochemistry 33 14144-14155.

Beishuizen A, Thijs LG, Haanen C \& Vermes I 2001 Macrophage migration inhibitory factor and hypothalamo-pituitary-adrenal function during critical illness. Journal of Clinical Endocrinology and Metabolism 86 2811-2816.

Bloom BR \& Bennett B 1966 Mechanism of a reaction in vitro associated with delayed-type hypersensitivity. Science $\mathbf{1 5 3}$ $80-82$.

Bozza M, Satoskar AR, Lin G, Lu B, Humbles AA, Gerard C \& David JR 1999 Targeted disruption of migration inhibitory factor gene reveals its critical role in sepsis. Journal of Experimental Medicine 189 341-346.

Bucala R 1996 MIF rediscovered: cytokine, pituitary hormone, and glucocorticoid-induced regulator of the immune response. FASEB Journal 10 1607-1613.
Calandra T, Bernhagen J, Mitchell RA \& Bucala R 1994 Macrophage is an important and previously unrecognized source of macrophagemigration inhibitory factor. Journal of Experimental Medicine $\mathbf{1 7 9}$ 1895-1902.

Calandra T, Bernhagen J, Metz CN, Spiegel LA, Bacher M, Donnelly T, Cerami A \& Bucala R 1995 MIF as a glucocorticoid-induced modulator of cytokine production. Nature 377 68-71.

Calandra T, Spiegel LA, Metz CN \& Bucala R 1998 Macrophage migration inhibitory factor is a critical mediator of the activation of immune cells by exotoxins of Gram-positive bacteria. PNAS $\mathbf{9 5}$ 11383-11388.

Calandra T, Echtenacher B, Roy DL, Pugin J, Metz CN, Hultner L, Heumann D, Mannel D, Bucala R \& Glauser MP 2000 Protection from septic shock by neutralization of macrophage migration inhibitory factor. Nature Medicine 6 164-170.

Chollet-Martin S, Gatecel C, Kermarrec N, Gougerot-Pocidalo MA \& Payen DM 1996 Alveolar neutrophil functions and cytokine levels in patients with the adult respiratory distress syndrome during nitric oxide inhalation. American Journal of Respiratory and Critical Care Medicine 153 985-990.

Churchill WHJ, Piessens WF, Sulis CA \& David JR 1975 Macrophages activated as suspension cultures with lymphocyte mediators devoid of antigen become cytotoxic for tumor cells. Journal of Immunology 115 781-786.

Claret FX, Hibi M, Dhut S, Toda T \& Karin M 1996 A new group of conserved coactivators that increase the specificity of AP-1 transcription factors. Nature 383 453-457.

Daun JM \& Cannon JG 2000 Macrophage migration inhibitory factor antagonizes hydrocortisone-induced increases in cytosolic IkappaBalpha. American Journal of Physiology. Regulatory, Integrative and Comparative Physiology 279 R1043-R1049.

David JR 1966 Delayed hypersensitivity in vitro: its mediation by cell-free substances formed by lymphoid cell-antigen interaction. PNAS 56 72-77.

De Bosscher K, Vanden Berghe W, Vermeulen L, Plaisance S, Boone E \& Haegeman G 2000 Glucocorticoids repress NF-kappaB-driven genes by disturbing the interaction of $\mathrm{p} 65$ with the basal transcription machinery, irrespective of coactivator levels in the cell. PNAS 97 3919-3924.

Denhardt DT 1996 Signal-transducing protein phosphorylation cascades mediated by Ras/Rho proteins in the mammalian cell: the potential for multiplex signalling. Biochemistry Journal 318 729-747.

Donn R, Alourfi Z, De Benedetti F, Meazza C, Zeggini E, Lunt T, Stevens A, Shelley E, Lamb R, Ollier WE et al. 2001 Mutation screening of the macrophage migration inhibitory factor gene: positive association of a functional polymorphism of macrophage inhibitory factor with juvenile idiopathic arthritis. Arthritis and Rheumatism 44 1782-1785.

Donnelly SC, Haslett C, Dransfield I, Robertson CE, Carter DC, Ross JA, Grant IS \& Tedder TF 1994a Role of selectins in development of adult respiratory distress syndrome. Lancet 344 215-219.

Donnelly SC, Strieter RM, Kunkel SL, Walz A, Steedman D, Grant IS, Pollok AJ, Carter DC \& Haslett C 1994b Chemotactic cytokines in the established adult respiratory distress syndrome and at-risk patients. Chest 105 98S-99S.

Donnelly SC, Haslett C, Reid PT, Grant IS, Wallace WAH, Metz CN, Bruce LJ \& Bucala R 1997 Regulatory role for macrophage migration inhibitory factor in acute respiratory distress syndrome. Nature Medicine 3 320-323.

Fernandes D, Guida E, Koutsoubos V, Harris T, Vadiveloo P, Wilson JW \& Stewart AG 1999 Glucocorticoids inhibit proliferation, cyclin D1 expression, and retinoblastoma protein phosphorylation, but not activity of the extracellular-regulated kinases in human cultured airway smooth muscle. American Journal of Respiratory Cell and Molecular Biology 21 77-88. 
Francis SE, Camp NJ, Dewberry RM, Gunn J, Syrris P, Carter ND, Jeffery S, Kaski JC, Cumberland DC, Duff GW et al. 1999 Interleukin-1 receptor antagonist gene polymorphism and coronary artery disease. Circulation $\mathbf{9 9} 861-866$.

Frantz AG \& Wilson JD 1992 Endocrine disorders of the breast. In Williams Textbook of Endocrinology, edn 8, pp 962-968. Eds JD Wilson \& DW Foster. Philadelphia, PA: Saunders.

Froidevaux C, Roger T, Martin C, Glauser MP \& Calandra T 2001 Macrophage migration inhibitory factor and innate immune responses to bacterial infections. Critical Care Medicine 29 S13-S15.

Greenberg AK, Hu J, Basu S, Hay J, Reibman J, Yie TA, Tchou-Wong KM, Rom WN \& Lee TC 2002 Glucocorticoids inhibit lung cancer cell growth through both the extracellular signal-related kinase pathway and cell cycle regulators. American Journal of Respiratory Cell and Molecular Biology 27 320-328.

Hayakawa M, Ishida N, Takeuchi K, Shibamoto S, Hori T, Oku N, Ito F \& Tsujimoto M 1993 Arachidonic acid-selective cytosolic phospholipase A2 is crucial in the cytotoxic action of tumor necrosis factor. Journal of Biological Chemistry 268 11290-11295.

Hudson JD, Shoaibi MA, Maestro R, Carnero A, Hannon GJ \& Beach DH 1999 A proinflammatory cytokine inhibits p53 tumor suppressor activity. Journal of Experimental Medicine 190 1375-1382.

Joshi PC, Poole GV, Sachdev V, Zhou X \& Jones Q 2000 Trauma patients with positive cultures have higher levels of circulating macrophage migration inhibitory factor (MIF). Research Communications in Molecular Pathology and Pharmacology 107 13-20.

Karin M 1998 New twists in gene regulation by glucocorticoid receptor: is DNA binding dispensable? Cell $\mathbf{9 3}$ 487-490.

Kay AB, Barata L, Meng Q, Durham SR \& Ying S 1997 Eosinophils and eosinophil-associated cytokines in allergic inflammation. International Archives of Allergy and Immunology 113 196-199.

Kleemann R, Hausser A, Geiger G, Mischke R, Burger-Kentischer A, Flieger O, Johannes FJ, Roger T, Calandra T, Kapurniotu A et al. 2000 Intracellular action of the cytokine MIF to modulate AP-1 activity and the cell cycle through Jab1. Nature 408 211-216.

Leech M, Metz C, Hall P, Hutchinson P, Gianis K, Smith M, Weedon H, Holdsworth SR, Bucala R \& Morand EF 1999 Macrophage migration inhibitory factor in rheumatoid arthritis: evidence of proinflammatory function and regulation by glucocorticoids. Arthritis and Rheumatism 42 1601-1608.

Leech M, Metz C, Bucala R \& Morand EF 2000 Regulation of macrophage migration inhibitory factor by endogenous glucocorticoids in rat adjuvant-induced arthritis. Arthritis and Rheumatism 43 827-833.

Liao H, Bucala R \& Mitchell RA 2002 Adhesion-dependent signaling by MIF. Journal of Biological Chemistry 278 76-81.

Makita H, Nishimura M, Miyamoto K, Nakano T, Tanino Y, Hirokawa J, Nishihira J \& Kawakami Y 1998 Effect of antimacrophage migration inhibitory factor antibody on lipopolysaccharideinduced pulmonary neutrophil accumulation. American Journal of Respiratory and Critical Care Medicine 158 573-579.

McGuire W, Hill AV, Allsopp CE, Greenwood BM \& Kwiatkowski D 1994 Variation in the TNF-alpha promoter region associated with susceptibility to cerebral malaria. Nature $371508-510$.

Meyer-Siegler K 2000 Macrophage migration inhibitory factor increases MMP-2 activity in DU-145 prostate cells. Cytokine $\mathbf{1 2}$ 914-921.

Mitchell RA, Metz CN, Peng T \& Bucala R 1999 Sustained mitogen-activated protein kinase (MAPK) and cytoplasmic phospholipase A2 activation by macrophage migration inhibitory factor (MIF). Regulatory role in cell proliferation and glucocorticoid action. Journal of Biological Chemistry 274 18100-18106.

Mitchell RA, Liao H, Chesney J, Fingerle-Rowson G, Baugh J, David J \& Bucala R 2002 Macrophage migration inhibitory factor (MIF) sustains macrophage proinflammatory function by inhibiting p53: regulatory role in the innate immune response. PNAS $\mathbf{9 9}$ $345-350$.
Nathan CF, Karnovsky ML \& David JR 1971 Alterations of macrophage functions by mediators from lymphocytes. Journal of Experimental Medicine 133 1356-1376.

Nathan CF, Remold HG \& David JR 1973 Characterization of a lymphocyte factor which alters macrophage functions. Journal of Experimental Medicine 137 275-290.

Nishino T, Bernhagen J, Shiiki H, Calandra T, Dohi K \& Bucala R 1995 Localization of macrophage-migration inhibitory factor (MIF) to secretory granules within the corticotropic and thyrotropic cells of the pituitary-gland. Molecular Medicine 1 781-788.

Oberholzer C, Oberholzer A, Clare-Salzler M \& Moldawer LL 2001 Apoptosis in sepsis: a new target for therapeutic exploration. FASEB Journal 15 879-892.

Ohmori Y \& Hamilton TA 1994 Regulation of macrophage gene expression by T-cell-derived lymphokines. Pharmacology and Therapeutics 63 235-264.

Onodera S, Kaneda K, Mizue Y, Koyama Y, Fujinaga M \& Nishihira J 2000 Macrophage migration inhibitory factor up-regulates expression of matrix metalloproteinases in synovial fibroblasts of rheumatoid arthritis. Journal of Biological Chemistry 275 444-450.

Onodera S, Nishihira J, Iwabuchi K, Koyama Y, Yoshida K, Tanaka S \& Minami A 2002 Macrophage migration inhibitory factor up-regulates matrix metalloproteinase- 9 and -13 in rat osteoblasts. Relevance to intracellular signaling pathways. Journal of Biological Chemistry 277 7865-7874.

Powe JE, Short A, Sibbald WJ \& Driedger AA 1982 Pulmonary accumulation of polymorphonuclear leukocytes in the adult respiratory distress syndrome. Critical Care Medicine 10 712-718.

Reil TD, Kashyap VS, Sarkar R, Freishlag J \& Gelabert HA 2000 Dexamethasone inhibits the phosphorylation of retinoblastoma protein in the suppression of human vascular smooth muscle cell proliferation. Journal of Surgical Research 92 108-113.

Roger T, David J, Glauser MP \& Calandra T 2001 MIF regulates innate immune responses through modulation of Toll-like receptor 4. Nature 414 920-924.

Rossi AG, Haslett C, Hirani N, Greening AP, Rahman I, Metz CN, Bucala R \& Donnelly SC 1998 Human circulating eosinophils secrete macrophage migration inhibitory factor (MIF) - potential role in asthma. Journal of Clinical Investigation 101 2869-2874.

Santos L, Hall P, Metz C, Bucala R \& Morand EF 2001 Role of macrophage migration inhibitory factor (MIF) in murine antigen-induced arthritis: interaction with glucocorticoids. Clinical and Experimental Immunology 123 309-314.

Sasaki Y, Kasuya K, Nishihira J, Magami Y, Tsuchida A, Aoki T \& Koyanagi Y 2002 Suppression of tumor growth through introduction of an antisense plasmid of macrophage migration inhibitory factor. International Journal of Molecular Medicine $\mathbf{1 0}$ $579-583$.

Satoskar AR, Bozza M, Rodriguez SM, Lin G \& David JR 2001 Migration-inhibitory factor gene-deficient mice are susceptible to cutaneous Leishmania major infection. Infection and Immunity 69 906-911.

Scheinman RI, Cogswell PC, Lofquist AK \& Baldwin ASJ 1995 Role of transcriptional activation of I kappa B alpha in mediation of immunosuppression by glucocorticoids. Science 270 283-286.

Singh P, Chan SW \& Hong W 2001 Retinoblastoma protein is functionally distinct from its homologues in affecting glucocorticoid receptor-mediated transcription and apoptosis. Journal of Biological Chemistry 276 13762-13770.

Tanino Y, Makita H, Miyamoto K, Betsuyaku T, Ohtsuka Y, Nishihira J \& Nishimura M 2002 Role of macrophage migration inhibitory factor in bleomycin-induced lung injury and fibrosis in mice. American Journal of Physiology. Lung Cellular and Molecular Physiology 283 L156-L162.

Thomas LH \& Warner JA 1996 The eosinophil and its role in asthma. General Pharmacology 27 593-597. 
Thomer MO, Vance ML, Horvath E \& Kovacs K 1992 The anterior pituitary. In Williams Textbook of Endocrinology, edn 8, pp 221-224. Eds JD Wilson \& DW Foster. Philadelphia, PA: Saunders.

Waeber G, Thompson N, Chautard T, Steinmann M, Nicod P, Pralong FP, Calandra T \& Gaillard RC 1998 Transcriptional activation of the macrophage migration-inhibitory factor gene by the corticotropin-releasing factor is mediated by the cyclic adenosine 3',5'-monophosphate responsive element-binding protein CREB in pituitary cells. Molecular Endocrinology 12 698-705.

Weinberg RA 1995 The retinoblastoma protein and cell cycle control. Cell 81 323-330.

Whyte M, Hubbard R, Meliconi R, Whidborne M, Eaton V, Bingle C, Timms J, Duff G, Facchini A, Pacilli A et al. 2000 Increased risk of fibrosing alveolitis associated with interleukin-1 receptor antagonist and tumor necrosis factor-alpha gene polymorphisms. American Journal of Respiratory and Critical Care Medicine 162 755-758.
Williams TE, Ayala A \& Chaudry IH 1997 Inducible macrophage apoptosis following sepsis is mediated by cysteine protease activation and nitric oxide release. Journal of Surgical Research $\mathbf{7 0}$ 113-118.

Yasuda Y, Kasuya K, Nishihira J, Sasaki Y, Tsuchida A, Aoki T \& Koyanagi Y 2002 Induction of cell arrest by transfection of macrophage migration inhibitory factor antisense plasmid. International Journal of Molecular Medicine 10 463-467.

Received in final form 19 June 2003

Accepted 26 June 2003

Made available online as an

Accepted Preprint 30 June 2003 